\title{
Angioplasty with drug-eluting stents versus bypass grafting for treatment of unprotected left main stem disease.
}

\author{
Ramlall M*, Costanzo P, Ali A and John J
}

Accepted on July 17, 2017

Medically treated patients with unprotected left main stem (LMS) coronary artery disease have a poor prognosis and early evidence suggests there is a strong survival benefit from surgical revascularization, especially in patients with left ventricular systolic dysfunction [1,2]. Furthermore, Ragosta et al. demonstrated that, in a cohort of patients with LMS disease, $80 \%$ had unfavourable characteristics for percutaneous coronary angioplasty (PCI), namely bifurcation disease, occlusion of a major coronary, left ventricular ejection fraction (LVEF) $<30 \%$, occlusion of a dominant right coronary artery (RCA), left dominant circulation, and Coexisting three-vessel disease, making it technically challenging [3]. Unsurprisingly, early data on LMS percutaneous intervention was not encouraging. An observational study analysing 279 consecutive patients who underwent unprotected LMS angioplasty with ballooning $+/$ - stenting showed the incidence of all-cause mortality at $13.7 \%$ in-hospital and $24.2 \%$ at 1 year [4].

Technological advancements in stent design and evolving procedural techniques however have yielded PCI results comparable to surgical therapy. Registry data subsequent to the advent of drug-eluding stents (DES) proved more encouraging with comparable outcomes with regards to mortality and major adverse cardiac and cerebrovascular events (MACCE) [5].

In 2011 the first randomised controlled trial (RCT) comparing PCI vs. CABG for patients with unprotected LMS disease enrolled 105 patients with $>50 \%$ stenosis assessed by coronary angiography [6]. The primary endpoint of improvement in LVEF, in patients treated with PCI versus CABG (58\%vs. $54 \%, p=0.047)$ was achieved. The incidence of MACCE was equivalent at 1 year in both groups. However the study was not powered for this outcome and only $35 \%$ of patients had DES implanted, with the remainder receiving bare metal stents (BMS). The findings were nevertheless encouraging.

The Synergy between PCI with Taxus and Cardiac Surgery (SYNTAX) trial LMS sub-group analysis included 705 patients treated with either PCI or CABG [7]. The primary endpoint of MACCE at 1 year, reported in 2009, was comparable in both groups (15.8\% vs. 13.7\%). The SYNTAX score, developed to objectively assess lesion complexity angiographically [8], was used to stratify patients in 3 cohorts-low, intermediate and high lesion complexity. This revealed no significant difference in MACCE rates in the low and intermediate groups, but $\mathrm{CABG}$ was significantly superior to PCI in patients with high SYNTAX score. The subsequent 5-year follow-up results showed a similar trend [9]. There was no significant difference in MACCE rates in both treatment groups for patients with low and intermediate lesion complexity. The high SYNTAX score cohort treated with $\mathrm{CABG}$ had significantly lower MACCE rates $(46.5 \%$ vs. $29.7 \%, \mathrm{p}=0.003)$ at 5 years.
The findings of 6 trials to date involving DES for unprotected LMS angioplasty are summarised in Table1. While many of the initial studies were under-powered or involved sub-group analysis $[10,11]$, the multi-centre EXCEL trial was designed to investigate no inferiority of PCI compared to $\mathrm{CABG}$ in patients with low intermediate SYNTAX scores and with 1905 patients randomised, it is the largest trial to date [12]. Its use of everolimus eluting stents (EES, Xience, Abbott Vascular, and USA) was more relevant to modern day clinical practice. The primary end-point of death, stroke or myocardial infarction occurred in $15.4 \%$ of the patients in the PCI group and in $14.7 \%$ of the patients in the CABG group $(p=0.98)$ at 3 years follow-up. Revascularisation rate was however significantly higher in the PCI cohort (12.9 vs. 7.6, $\mathrm{p} \leq 0.001)$. Of relevance, repeat revascularisation was not included in the composite primary end point. Interestingly, contrary to the findings of the SYNTAX trial, there was no significant difference in the rate of stroke at 30 days and 3 years follow up. The event rate for this outcome was however low at 30 days.

The Nordic-Baltic-British Left Main Revascularization Study (NOBLE) trial is also a multicentre trial comparing the use of biolimus eluting stent (BES, Bio matrix, Biosensors, Singapore) stent versus CABG [13]. Though patients with high SYNTAX scores were not excluded, $91.3 \%$ of patients recruited were classed as having $\mathrm{CAD}$ of either low or intermediate complexity as patients with $>3$ lesions were excluded.

At 5 years, Kaplan-Meier estimate for MACCE (composite outcome of all-cause mortality, non-procedural MI, repeat coronary revascularisation and stroke) in the PCI and CABG arms were $29 \%$ and $19 \%$ respectively $(p=0 \cdot 0066)$. There was no significant difference in the rates of all-cause mortality and stroke at 5 years, although the risk of stroke was higher for the CABG arm at 30 days. One major limitation of this study was that it did not achieve its anticipated event rate despite extending the follow-up period. It is also worth noting that first generation stents were used for the first $10 \%$ of the patients enrolled and that per procedural MI was not included in the outcome.

A meta-analysis of 5 RCTs published by Sardar et al. [14] provided a snapshot of the main findings from the evidence gathered so far. It demonstrated no significant difference in MACCE, stroke and all-cause mortality at an average follow up of 3.4 years. Revascularisation rates were however significant higher in the PCI group.

Current evidence suggests that advancements in stent design have rendered PCI a viable therapeutic option to surgery for patients with unobstructed LMS disease. Though numerous observational studies comparing PCI versus CABG have been conducted, only a limited number of large adequately powered 
Citation: Ramlall M, Costanzo P, Ali A, John J. Angioplasty with drug-eluting stents versus bypass grafting for treatment of unprotected left main stem disease. Curr Trend Cardiol. 2017;1(2):39-40.

RCTs exist. Even though there are a few trends emerging in the data so far, more robust studies are required to firmly establish the role of PCI.

Table 1: Summary of randomised-controlled trials with drug-eluting stents comparing PCI vs. CABG for treatment of unprotected LMS disease. (PCI: percutaneous coronary intervention, CABG: coronary artery bypass grafting, FU: follow-up, MI: myocardial infarction, RR: Revascularisation rate, CVA: cerebrovascular accident, MACCE: major adverse cardiac and cerebrovascular event, SES: serolimus eluting stens, PES: paclitaxel eluting stent, EES: everolimus-eluting stents, BES: biolimus eluting stent). *Denotes p value for non-inferiority.

\begin{tabular}{|c|c|c|c|c|c|c|c|c|c|c|}
\hline Study & Year & $\begin{array}{l}\text { Number } \\
\text { PCI/ } \\
\text { CABG }\end{array}$ & $\begin{array}{l}\text { FU } \\
\text { (median } \\
\text { years) }\end{array}$ & Syntax Score & Stent & Death & MI & $\mathbf{R R}$ & CVA & MACCE \\
\hline Boudriot et al. & 2011 & $100 / 101$ & 1 & - & SES & $2.0 / 5.0$ & $3.0 / 3.0$ & $14.0 / 5.9\left[0.35^{*}\right]$ & - & $19 / 13.9\left[0.19^{*}\right]$ \\
\hline Park et al. & 2011 & $300 / 300$ & 2 & $67.7 \%$ score $\leq 29$ & SES & $2.4 / 3.4[0.34]$ & $1.7 / 1.0[0.49]$ & $9.0 / 4.2[0.02]$ & $0.4 / 0.7[0.56]$ & $12.2 / 8.1$ \\
\hline $\begin{array}{l}\text { Morice et } \begin{array}{l}\text { al. } \\
\text { SYNTAX } \\
\text { study }\end{array} \\
\text { sub- }\end{array}$ & 2014 & $357 / 348$ & 5 & $59.5 \%$ score $\leq 32$ & PES & $12.8 / 14.6[0.53]$ & $8.2 / 4.8[0.10]$ & $26.7 / 15.5[0.01]$ & $1.5 / 4.3[0.03]$ & $\begin{array}{l}36.9 / 31.0 \\
{[0.12]}\end{array}$ \\
\hline $\begin{array}{l}\text { Ahn et al. } \\
\text { PRECOMBAT }\end{array}$ & 2015 & $300 / 300$ & 5 & $77.4 \%$ score $\leq 32$ & SES & $5.7 / 7.9$ [0.32] & $2.0 / 1.7[0.76]$ & $11.4 / 5.5$ [0.012] & $0.7 / 0.7$ [0.99] & $\begin{array}{l}17.5 / 14.3 \\
{[0.26]}\end{array}$ \\
\hline $\begin{array}{l}\text { Stone et al. } \\
\text { EXCEL }\end{array}$ & 2016 & $948 / 957$ & 3 & $\leq 32$ & EES & $8.2 / 5.9[0.11]$ & $8.0 / 8.3[0.64]$ & $12.9 / 7.6[0.001]$ & $2.3 / 2.9[0.37]$ & $\begin{array}{l}15.4 / 14.7 \\
{[0.98]}\end{array}$ \\
\hline $\begin{array}{l}\text { Mäkikallio et al. } \\
\text { NOBLE }\end{array}$ & 2016 & $592 / 592$ & 3.1 & $91.3 \%$ score $\leq 32$ & BES & $12-09-2017$ [0.77] & $7 / 2[0.004]$ & $16 / 10$ [0.032] & $5 / 2[0.073]$ & $29 / 19[0.0066]$ \\
\hline
\end{tabular}

\section{References}

1. Caracciolo EA, Davis KB, Sopko G, et al. Comparison of surgical and medical group survival in patients with left main equivalent coronary artery disease. Long-term CASS experience. Circulation. 1995;91:2335-44.

2. Lee $\mathrm{CH}$, Ahn JM, Lee PH, et al. Comparative determinants of 5-year cardiovascular event rates in patients with unprotected left main coronary artery disease. Coron Artery Dis. 2017;28:387-94.

3. Ragosta M, Dee S, Sarembock IJ, et al. Prevalence of unfavorable angiographic characteristics for percutaneous intervention in patients with unprotected left main coronary artery disease. Catheterization and cardiovascular interventions. 2006;68:357-62.

4. Tan WA, Tamai H, Park SJ, et al. Long-term clinical outcomes after unprotected left main trunk percutaneous revascularization in 279 patients. Circulation. 2001;104:1609-14.

5. Chieffo A, Morici N, Maisano F, et al. Percutaneous treatment with drugeluting stent implantation versus bypass surgery for unprotected left main stenosis: a single-center experience. Circulation. 2006;113:2542-7.

6. Boudriot $\mathrm{E}$, Thiele $\mathrm{H}$, Walther $\mathrm{T}$, et al. Randomized comparison of percutaneous coronary intervention with sirolimus-eluting stents versus coronary artery bypass grafting in unprotected left main stem stenosis. J Am Coll Cardiol. 2011;57:538-45.

7. Morice MC, Serruys PW, Kappetein AP, et al. Outcomes in patients with de novo left main disease treated with either percutaneous coronary intervention using paclitaxel-eluting stents or coronary artery bypass graft treatment in the Synergy Between Percutaneous Coronary Intervention with TAXUS and Cardiac Surgery (SYNTAX) trial. Circulation. 2010;121:2645-53.

8. Sianos G, Morel MA, Kappetein AP, et al. The SYNTAX Score: an angiographic tool grading the complexity of coronary artery disease. EuroIntervention. 2005;1:219-27.
9. Morice MC, Serruys PW, Kappetein AP, et al. Five-year outcomes in patients with left main disease treated with either percutaneous coronary intervention or coronary artery bypass grafting in the synergy between percutaneous coronary intervention with taxus and cardiac surgery trial. Circulation. 2014;129:2388-94

10. Park SJ, Kim YH, Park DW, et al. Randomized trial of stents versus bypass surgery for left main coronary artery disease. NEJM. 2011;364:1718-27.

11. Ahn JM, Roh JH, Kim YH, et al. Randomized Trial of Stents Versus Bypass Surgery for Left Main Coronary Artery Disease: 5-Year Outcomes of the PRECOMBAT Study. J Am Coll Cardiol. 2015;65:2198-206.

12. Stone GW, Sabik JF, Serruys PW, et al. Investigators ET. Everolimus-Eluting Stents or Bypass Surgery for Left Main Coronary Artery Disease. NEJM. 2016;375:2223-35.

13. Makikallio T, Holm NR, Lindsay M, et al. Percutaneous coronary angioplasty versus coronary artery bypass grafting in treatment of unprotected left main stenosis (NOBLE): a prospective, randomised, open-label, non-inferiority trial. Lancet. 2016;388:2743-52.

14. Sardar P, Giri J, Elmariah S, Chatterjee S, et al. Meta-Analysis of DrugEluting Stents Versus Coronary Artery Bypass Grafting in Unprotected Left Main Coronary Narrowing. Am J Cardiol. 2017;119:1746-52.

\section{"Correspondence to}

Manish Ramlall,

Castle Hill Hospital

United Kingdom 